\title{
The Unresolved Identity of that Relative Clauses
}

\author{
Wonseok Kim ${ }^{1}$ \\ ${ }^{1}$ Department of English Language and Literature, Yonsei University, Korea \\ Correspondence: Wonseok Kim, Department of English Language and Literature, Yonsei University, Seongsan-Ro \\ 262, Seodaemun-Gu, Seoul, Korea. Postal Code: 120-749. E-mail: kws3255@korea.com
}

Received: November 26, 2013

Accepted: December 16, 2013

Online Published: December 17, 2013

doi:10.5430/elr.v2n2p96

URL: http://dx.doi.org/10.5430/elr.v2n2p96

\begin{abstract}
The conundrum of the identity of that relative clauses has drawn a considerable amount of attention from researchers in various fields of linguistics such as historical linguistics, syntax, and semantics, to name a few. The central issues are i) the status of relative that, ii) fundamentally different syntactic analyses, partly due to the different view on the status of that, iii) alternation issue of that vs. wh-relative pronouns, iv) different semantic analyses of that relative clauses, v) discrete discourse function analyses of that relative clauses. Regarding these central issues, this study has three goals: i) to conduct a comprehensive literature review and examine these issues qualitatively, with the aid of corpora (ICE-GB and COHA used); ii) to provide some insight and resolutions, if possible, to each issue, iii) to expand the horizons of delineating the identity of that relative clauses more comprehensively than before. With the comprehensive literature review and corpus research, this study attempts to resolve and provide some solutions and suggestions to this conundrum. Finally, this study expands the horizons of delineating the identity of that relative clauses more comprehensively, so that it can be helpful in subsequent research.
\end{abstract}

Keywords: that relative clause, Relative that, Different syntactic analyses, Alternation, Semantic meanings, Discourse function

\section{Introduction}

\subsection{The Identity of that Relative Clauses as a Stumbling Block}

English relative clauses have been extensively studied in almost every field of linguistics, as shown by the following examples:

1) Syntax (e.g., Sag, 1997; de Vries, 2002: 126-127; Culicover, 2009: 339-344, 358-360; Radford, 2009: 223-227; Culicover, 2011)

2) Semantics (e.g., Lee, 1994; Soh, 1995)

3) Phonology (e.g., Jeon, Shin, \& Kim, 2007)

4) Pragmatics; discourse analysis (e.g., Wiesemann, 2009: 91, 131; Tse \& Hyland, 2010)

5) Applied Linguistics; psycholinguistics; cognitive linguistics (e.g., Diessel \& Tomasello, 2005; Jaeger \& Wasow, 2006; Lee, 2008)

6) Historical linguistics/variation and language change (e.g., Romaine, 1980; Fischer, 1992: 295-310; Traugott, 1992: 223-233; Ball, 1996; Denison, 1998: 274-292; Newbrook, 1998; Rissanen, 1999: 292-301 )

7) Referential grammar (e.g., Quirk, Greenbaum, Leech, \& Svartvik, 1985: 1243-1260; Biber, Johansson, Leech, Conrad, \& Finegan, 1999: 608-630; Huddleston \& Pullum, 2002: 1033-1096)

There are two common problems found in these studies. One problem is how to view that relative clauses, that is, as a relative clause introduced by a complementizer that or as a relative clause introduced by a relative pronoun that. The other problem is whether a that relative clause is always used as a restrictive relative clause. Regarding the first problem that originates from the different perspectives on the status of that, Auwera (1985) states that it is a "centennial dispute" and concludes that the relative that is "a highly pronominal relativizer" (see p. 149, 175), not a complementizer. Quirk et al. (1985) consider it to be a relative pronoun. On the other hand, derivational generative grammarians like Avram Noam Chomsky and Andrew Radford consider relative that to be a complementizer. Because of these conflicting views on the status of that, the status of that relative clauses also changes, either to a complementizer phrase (CP) or to a relative clause introduced by a relative pronoun. As Auwera (1985) states, "every 
grammarian of English, whatever his or her theoretical conviction, is confronted with [this issue]" (p. 149).

With respect to the second problem, that is, whether that relative clauses are only used as restrictive relative clauses, the current dominant view is that this is indeed the case. This was, however, not true during the Middle English and Early Modern English periods, during which that relative clauses had been used both as restrictive relative clauses and nonrestrictive relative clauses (see Fischer, 1992: 296; Rissanen, 1999: 293; Millward, 2012: 262). This old nonrestrictive usage of that relative clauses is still limitedly common as Jacobsson (1994) points out giving numerous examples. Sonoda (2006) also argues that that relative clauses are still used both as restrictive and nonrestrictive clauses in much the same way that the relative pronoun which is used, most commonly witnessed in British English.

These two common problems have been repeatedly addressed by the researchers who study English relative clauses because it is impossible to proceed with research on English relative clauses without taking a clear position on these two problems. In other words, depending on the chosen view of the identity of that relative clauses, subsequent analyses can be significantly different. For instance, with regard to terminology, in an effort to avoid the dispute, many researchers adopt neutral words to name the relative that, such as 'relativizer' or 'relative (clause) marker.' When researchers choose one position on the status of that they use either 'relative pronoun' or 'complementizer.' Moreover, in syntax, as stated above, it can be consequently considered either as a complementizer phrase or as a relative clause introduced by a relative pronoun. In addition, regarding an alternation issue such as who vs. that for an animate antecedent, it can be viewed as an alternation between an empty or null operator suggested by Chomsky (see Hornstein, Nunes, \& Grohmann, 2005: 27) and the relative pronoun who. Furthermore, if that relative clauses are also used as nonrestrictive relative clauses, then current semantic and discourse function analyses concerned with that relative clauses should be altered because it is most often believed that a restrictive relative clause has an intersective meaning or denotes a subset of the reference of the head with identification discourse function. On the other hand, a nonrestrictive clause can have not only truth conditional meanings (see Huddleston \& Pullum, 2002: 1063) but may also carry other meanings such as concession or result (see Jacobsson, 1994: 193), and a more possibly diverse range of discourse functions (see Huddleston \& Pullum, 2002: 1063; Quirk et al., 1985: 803-806).

In addition to these two problems, that relative clauses behave differently from wh-relative clauses in terms of formality, sociolinguistic variables, and some linguistic features. For these reasons, the identity of that relative clauses has been a stumbling block for researchers who have studied English relative clauses, not to mention a great source of confusion to English learners.

\subsection{Central Issues to Address}

To solve this conundrum of the identity of that relative clauses, there have been a considerable number of studies by researchers in various fields of linguistics such as historical linguistics, syntax, and semantics. The central issues that have been tackled ceaselessly by researchers are as follows (Note 1):

1) The status of that: complementizer vs. relative pronoun (e.g., Jespersen, 1961: 165-168; Auwera, 1985; Quirk et al., 1985; Sag, 1997: 462-464; Radford, 2004a: 228-229, 2004b: 176; Kim \& Sells, 2008: 233-235; Culicover, 2009: 358-360)

2) Fundamentally different syntactic analyses, partly due to the different view on the status of that (e.g., Chomsky, 1995: 70-71; Sag, 1997: 462-464; Haegeman \& Gue'ron, 1999: 185-199; Radford, 2004a: 228-231; Hornstein et al., 2005: 277-279)

3) Alternation issue of that vs. wh-relative pronouns (e.g., Quirk, 1957; Sigley, 1997a, 1997b; Biber et al., 1999: 608-630; Moon, 2012)

4) Different semantic analyses of that relative clauses (e.g., Quirk et al., 1985: 290, 385, 784; Lee, 1994; Soh, 1995; Huddleston \& Pullum, 2002: 1064-1065)

5) Discrete discourse function analyses of that relative clauses (e.g., Quirk et al., 1985: 367; De Haan, 1987: 174; Fox \& Thompson, 1990; Hardy \& Milton, 1994; Wiesemann, 2009: 91, 131; Tse \& Hyland, 2010)

These central issues are addressed comprehensively, critically, and qualitatively in this study.

\subsection{The Objective and Outline of the Study}

This study has three goals: i) to conduct a comprehensive literature review and examine these issues qualitatively, with the aid of corpora (ICE-GB and COHA used); ii) to provide some insight and resolutions, if possible, to each issue; iii) to expand the horizons of delineating the identity of that relative clauses more comprehensively than 
before.

Section 2 covers a preliminary review of the issues mentioned in subsection 1.2. Section 3 discusses all the issues qualitatively, providing empirical evidence when necessary and offers some solutions and suggestions. Section 4 attempts to delineate the identity of that relative clauses. Section 5 finalizes this study with a conclusion.

This study is more closely oriented to some comprehensive literature reviews and to presenting some solutions and suggestions regarding the identity of that relative clauses. Hopefully, this research will contribute to resolving the conundrum of the identity of that relative clauses.

\section{Preliminary Review of the Issues}

\subsection{Basic Sketch of that Relative Clauses}

That relative clauses (henceforth that-RC) can be represented as in (1).

(1) I know two girls $s_{i}\left[\right.$ that $_{i}$ bought a ticket last night].

The bracketed relative clause is often treated as an adjunct or a modifying clause of the preceding NP. The preceding NP two girls is called the 'head' or 'antecedent'. Depending on one's view, the head is the nominal girls, not two girls, since the semantic scope of the that-RC above doesn't include the quantifier. The underlined part is a subject gap, and that or the head is a filler, depending on the adoption of a certain syntactic theory (see Bhatt, 2002) (Note 2). Moreover, the head, that, and the gap are coreferential as indicated with the same coindex if the relative that is considered as a relative pronoun (see Note 3 ).

A that-RC is claimed to be used only as a restrictive relative clause (hereafter RRC) that 'identifies' the head in the context, differing from nonrestrictive relative clauses (henceforth NRRC). An RRC has a close continuous prosodic connection with the head in an utterance, and it is not set apart from the head by a comma in a written text.

A that-RC is often introduced by that attractors such as superlatives, some indefinite determiners, and certain determiners.

(2) This is the best class [that I've ever taken].

\subsection{The Status of that: Complementizer vs. Relative Pronoun}

There are two sharply divided views on the status of that which introduces an RRC. One view derives from the derivational generative grammar (e.g., Radford, 2004a: 228-229, 2004b: 176), and the other from the non-derivational generative grammar, traditional school, and EFL \& ESL grammar (e.g., Swan 1996: 490; Sag, 1997; Kim \& Sells, 2008: 233-235).

The derivational generative grammar treats that as a complementizer. In other words, the two thats in (3a) and (3b) are considered to belong to the same grammatical category, i.e., complementizer.

(3) a. She thinks that Tom is amused at the news.

b. She thinks of the letter [that she wrote the other day].

Radford (Radford, 2004a: 228-229, 2004b: 176) provides the following reasons: the homophonous pronunciation /ðat/ between the complementizer that and the relative that; the inability to introduce an infinitival relative clause; invariant form lacking the genitive one; no pied-piping.

However, in the case of the latter that considers the relative that as a relative pronoun, Kim and Sells (Kim \& Sells, 2008: 233-235) list the following counter evidence and arguments: the possibility of coordination between wh-RRC and that-RRC; no accusative case for that, thus making it impossible to form a pied-piped construction; and the similarity between who and that in terms of the inability to form a pied-piped construction. Auwera (1985) provides more comprehensive counter evidence including the usage of the genitive form that's in some English varieties as well as the adverbial usage of that as in 'the day that.' Auwera (1985: 174-175) argues that this relative that has the dual properties of a preposition and a relative pronoun, thus resisting pied-piping.

According to Auwera, this dispute has lasted for a century, causing some obstacles to English linguistic researchers and English learners around the world.

\subsection{Fundamentally Different Syntactic Analyses}

Because of these markedly divided views on the status of the relative that, syntax researchers have performed significantly different syntactic analyses, specifically in the field of derivational generative grammar and Head Driven Phrase Structure Grammar (HPSG), a non-derivational generative grammar. 
Derivational generative grammar, which was pioneered by Noam Chomsky, has undergone several paradigm shifts. The most recent paradigm is called "the Minimalist Program". Among many derivational generative grammarians, Radford (e.g., 2004a, 2004b, 2009) is the one who has conducted numerous analyses on the relative clause constructions. (4) shows how a that-RC is derived (from Radford 2004a: 230):

(4) a. [C that $\left.{ }_{\mathrm{WH}, \mathrm{EPP}}\right]$ [TP you [T can] [vp [v trust] who]] (Radford's (116))

b. [cР who [C that ${ }_{\text {WH, EPP }}$ [тр you [T can] [vp [v trust] whe]]] (Radford's (117))

c. [CP [C that $_{W H, \text { EPP }}$ [TP you [T can] [vр [v trust]

According to Radford (2004a: 230-231), the mergers between trust and who, and then between that and TP occur consecutively as in (a). After that, the [WH, EPP] features of that attract who to the [SPEC, CP]. Since the feature checking is done, the features and who trace copies are deleted, resulting in (b). The Multiply Filled COMP Filter and Relative Pronoun Spellout Condition or the lexical property of the relative that interact as constraints, resulting in (c) with who having a null spellout at PF.

In HPSG, Sag (1997) has provided the most comprehensive non-derivational syntactic analyses of relative clauses. According to Sag (1997: 462-464), there is no difference in generating that-RCs and wh-RRCs. Sag explains relativization through type hierarchy and constraints. In case of generating a subject relative clause, it inherits or interacts with the following constraints: Head Feature Principle, Valence Principle, Empty COMPS Constraint from $h d-p h$; SLASH (=gap) Inheritance Principle, Wh-Inheritance Principle from $h d$-nexus-ph; $h d$-subj-ph constraint; fin-hd-subj-ph constraint; rel-cl constraint; wh-rel-cl constraint; and wh-subj-rel-cl constraint. After the subject relative clause is formed, it combines with an NP, forming an $h d$-rel-ph, which is a subtype of a head-adjunct phrase as the relative clause functions as an adjunct.

In general, these different analyses are great barriers to the progressing of researchers' analyses of relative clause constructions because they have to adopt one theory rather than conflating them in a constructive way, and are also a source of great confusion to English educators and learners around the world.

\subsection{Alternation Issue of that vs. wh-relative Pronouns}

Another controversial decades-long dispute concerns the alternation issue between that and wh-relative pronouns (see e.g., Quirk, 1957; Sigley, 1997a, 1997b; Biber et al. 1999: 608-630; Moon 2012).

(5) a. Susan has a horse [that is of African origin].

b. Susan has a horse [which is of African origin].

As shown in the examples above, that and which can alternate with each other. To explain this variation phenomenon, most researchers have adopted a multifactorial approach by considering language-internal (e.g., animacy of the head; degree of definiteness of determiners and the head; length of an RRC; information structure) and language-external factors (e.g., age, gender, social class, ethnicity, region, and genre). However, there are no clear-cut empirical comprehensive explanations for this variation, as researchers give uncomparable or inconsistent factors using different research settings. For example, Quirk (1957) examined relative clause alternation using a corpus that represents educated British English. Sigley (1997) focused on the relativizer alternation found in New Zealand English. Biber et al. (1999: 608-630) often disregarded the animacy of the head in his analyses due to historical reasons, whereas many other researchers have considered it. Moon (2012) studied relative pronoun alternation mostly found in American English, discounting the effect of appositive clauses/noun complement clauses (e.g., the fact that Tom lost his book).

In general, this variation or alternation issue still remains as an unresolved, ongoing topic for researchers.

\subsection{Different Semantic Analyses of that Relative Clauses}

Depending on the position regarding the status of that and the subsequent theory adopted, the meaning of a that-RC is analyzed differently (as stated in Note 1, this issue is more concerned with the overall semantic analysis of RRCs). There is, however, a dominant view on the meaning of an RRC based on a set theory. That is, an RRC carries an intersective meaning with the head (see Bhatt, 2002: 44; Huddleston \& Pullum 2002: 1064).

Soh (1995) analyzes the intersective meaning of an RRC based on HPSG, using the compositionality principle, the semantic principle, the adjunct meaning assignment principle, a feature structure, and a head-driven approach. Soh claims that HPSG also effectively deals with the meaning of a relative clause and a head noun with a quantifier. The following is Soh's analysis for John hates everyman who likes a rival. 
(6) John hates everyman who likes a rival. (From Soh's (40d) in Soh, 1995: 36)

$$
\left(\forall \mathrm{x}_{1}:\left\{\operatorname{man}\left(\mathrm{x}_{1}\right)\right\}\right) \operatorname{hate}\left(\mathrm{J},\left(\mathrm{x}_{1}:\left\{\operatorname{man}\left(\mathrm{x}_{1}\right),\left(\left(\exists \mathrm{x}_{2}:\left\{\operatorname{rival}\left(\mathrm{x}_{2}\right)\right\}\right), \operatorname{like}\left(\mathrm{x}_{1}, \mathrm{x}_{2}\right)\right)\right\}\right)\right)
$$

Every has a wide scope, and the existential meaning has a narrow scope over the VP of the relative clause. The nominal man and the relative clause have the intersective meaning. Coindexation is used to indicate the same reference. The whole meaning of the sentence is composed of the parts.

Lee (1994) examined the reason for the ambiguity (an existential meaning vs. a generic meaning) in the meaning of a bare head noun with no explicit quantifier. He claims that semantic types of NPs result in such an ambiguity.

Quirk et al. (1985: 290, 385, 784) provide different meanings of an RRC.

(7) The Chicago [that I like] ['the aspect of Chicago']. (Slightly modified from Quirk et al., 1985: 290)

According to Quirk et al., an NP has a 'partitive meaning' when a proper noun with a definite article the is combined with an RRC.

(8) I am well aware of the many dangers [that we face]. (Slight modification of [3] in Quirk et al., 1985: 385)

Moreover, when the quantifier with the is combined with an RRC, it has a non-restrictive meaning as in (9).

(9) I am well aware of the dangers that we face - and there are many of them. (Slight modification of [3a] in Quirk et al., 1985: 385)

Quirk et al. also state that when a generic head and an RRC become merged, the NP can have a conditional meaning.

(10) Students that have any complaints should raise their hands. (Slight modification of (vi) in Quirk et al., 1985: 784)

['If students have any complaints, they should raise their hands.']

Huddleston and Pullum (2002: 1065) state that an indefinite NP modified by a restrictive relative clause can have both RRC and NRRC meanings, but one meaning can be properly chosen through information packaging. In this case, the RRC meaning carries essential information for the whole sentence or the context rather than the subset information of the head.

(11) A: Have you been to Paris? B: Yes, often: I have a brother [that lives there]. (Slight modification of (20 ii) in Huddleston \& Pullum, 2002: 1065)

The relative clause in B's answer contains crucial information for A's question.

As discussed so far, the common belief that an RRC has an intersective meaning should be modified. In reality, RRCs can have intersective meanings, partitive meanings, conditional meanings, essential contextual meanings, or in certain cases they can be ambiguous between NRRC and RRC meanings.

Moreover, when we consider that relative that was previously used in an RRC and an NRRC in Early Modern English and is still used in NRRCs frequently (as argued by Auwera, 1985: 155; see Sonoda, 2006; Millward \& Hayes, 2012: 262), the semantic meaning of that-RCs is still problematic because an NRRC has a propositional content (see Huddleston \& Pullum, 2002: 1063). Thus, because of the vestige of the early NRRC usage of that, that-RCs can take on a variety of meanings when we look at empirical corpus data. Hence, the meanings of that relative clauses should be still further explored.

\subsection{Discrete Discourse Function Analyses of that Relative Clauses}

The issue of discourse function analyses of RRCs has also been a major subject of interest for many researchers (e.g., Quirk et al., 1985: 367; De Haan, 1987: 174; Fox \& Thompson, 1990; Hardy \& Milton, 1994; Wiesemann, 2009: 91, 131; Tse \& Hyland, 2010). Many researchers, however, have suggested inconsistent discourse functions.

Quirk et al. (1985: 367) mention that a that-RC can have the function of characterization when the head is in a complement position. In (12), the that-RC characterizes the head.

(12) She's not the brilliant dancer [that she used to be].

De Haan (1987: 173-174) states that an RRC has describing, classifying, and identifying functions.

(13) An example of describing:

Q: What sort of table did you buy? (De Haan's (3a) in p. 173)

Ans: A table [that can be folded up] (De Haan's (3d) in p. 173) 
(14) An example of classifying

Cats [that wear gloves] catch no mice. (De Haan's (4) in p.174)

Wiesemann (2009: 131) argues that there are only two functions available for RRCs: identification and classification (that is, relativization results in a new subset of reference).

Concerning genre-specific discourse function studies, researchers attempt to make finer distinctions between the relative clause discourse functions. Fox and Thompson (1990) mention that information packaging plays an important role in explaining the distributional status of the combination of the head and the gap/relative clause type of RRCs, such as SO (in an SO relative clause type, the head is the subject and the gap is the object) in conversation. They also mention that relative clauses have three noteworthy functions: i) characterization or description of the head, new to the hearer; ii) identification of the head, known to the hearer previously (p.301-302); iii) anchoring the head to the given information in a discourse. Tse and Hyland (2010) studied discourse functions of RRCs and NRRCs found in journal descriptions. They claim that relative clauses are used for evaluation and persuasion. Their fine classifications are scope (mentioning the scope of a journal), clarity, and evaluation (see p. 10). In case of Hardy and Milton (1994), they claim that in literature, anchoring and characterization are prominent discourse functions (see $\mathrm{p}$. 251) (Note 4).

Overall, there are two types of studies, one focusing on general discourse functions and the other focusing on genre/register specific fine distinctions. These studies, despite expressing some shared perspectives, show different, subjective categories in many cases, creating the necessity for refinement and consistency. Moreover, since that-RCs can be used as non-restrictive relative clauses, the possible discourse functions expand, and when we consider different genres, there are still many subcategories of discourse functions to be discovered.

\section{An Attempt to Resolve the Conundrum of the Identity of that Relative Clauses}

\subsection{Status of that as "a Highly Pronominal Relativizer"}

This subsection examines the validity of the argument that relative that is a complementizer by examining empirical corpus data, and discusses the results.

\subsubsection{Methodology}

Radford (2004a: 228-229, 2004b: 176) argues that relative that is a complementizer, and the reasons mentioned in subsection 2.2 are listed again here for readers: i) the homophonous pronunciation /ठət/ between the complementizer that and the relative that; ii) inability to introduce an infinitival relative clause; iii) invariant form lacking the genitive one; iv) no pied-piping.

To discover whether or not counter examples exist, the Corpus of Historical American English (COHA) is used (see Davies, 2010-) (Note 5). COHA is a historical written corpus that has 400 million words produced between 1810 and 2009.

To search for counter examples, the search strings below were used with the adjustment of options (Freq 1000 and KWIC 1000).

1) For pied-piped that infinitivals: [nn*] [i*] that to $\left[\mathrm{v}^{*}\right]$

2) For non pied-piped that infinitivals: [nn*] that to $\left[\mathrm{v}^{*}\right]$

3) Genitive that's: [nn*] that 's [nn*] [v*]

4) Pied-piped that finite clause: $\left[\mathrm{nn}^{*}\right]\left[\mathrm{i}^{*}\right]$ that $\left[\mathrm{at}^{*}\right]\left[\mathrm{nn}^{*}\right]\left[\mathrm{v}^{*}\right]$

After obtaining the results, the concordance lines were reviewed one by one in order to find counter examples.

\subsubsection{Results}

For the pied-piped that infinitival, the following case (15) is found. The italicized is the search result with the possible pied-piped that infinitival relative clause bracketed. (Since it is ambiguous about what that refers to, it may not be the proper case. Moreover, there could have been some inversion for literary effects). If this is not the proper case, it seems that there is no proper example for the pied-piped that infinitival construction in COHA.

(15) (A case with the extended context, written in 1882 from COHA; see Note 6 for the text source)

[...] Thy fellowship was my culture, noble friend: By the hand thou took'st me, and did'st condescend To bring me straightway into thy fair guild; And life-long hath it been high compliment [By that to have been known], and thy friend styled, Given to rare thought and to good learning bent; Whilst in my 
straits an angel on me smiled. Permit me, then, thus honored, still to be A scholar in thy university. [...]

In case of the non pied-piped that infinitival construction, a case like (16) is found.

(16) (Text written in 1969, from COHA)

At the end of the summer I paid \$1,100 for a 1958 Mercedes, and that made life slightly easier in Los Angeles, because it's the kind of place [that to get anywhere] -- even the drugstore -- you've got to drive five miles.

In (16), place that to get can be paraphrased as place from which to get. This sentence seems to be the case where the adverbial relative that is used since when a head is, for example, place or day, a pied-piped preposition can be omissible. Auwera (1985: 174) argues that this kind of example doesn't rebut the pronominal status of the relative that because place could still be viewed as an antecedent and this 'adverbial' that usage co-occurs with specific types of words such as place, not street.

Overall, with respect to that infinitival constructions, it seems that COHA has no proper counter examples.

However, as Radford admitted, some examples of the genitive usage are found as in (17).

(17) (Fiction written in 1841, from COHA)

[...] speak out like a bold man [that's jest got the truth]

Pied-piped finite that relative clauses couldn't be found with the search string.

\subsubsection{Discussion}

It seems that with the exception of the genitive usage of relative that, COHA doesn't produce any counter examples against Radford's reasons listed in subsection 3.1.1. Then, do we still have to say that relative that is a complementizer? This is another issue. First, in case of the homophonous pronunciation /ठət/, we know that many Americans, especially young people under the age of 30 , pronounce a relative that, a complementizer that, a demonstrative pronoun that, and a determiner that in the same way, aside from the duration and accent. Moreover, when the four types of that follow a pause or precede a pause (supported by Jacobsson, 1994: 191), there isn't a big difference among the four thats. Then, is it possible to claim that all the four types of that are under the same category, 'complementizer'?

Second, no pied-piped that infinitival relative clauses can be rebutted with the fact that within COHA there are no pied-piped who infinitival relative clauses either (with the search string: [nn*] [i*] who to [vv0*]). An absence of pied-piped finite that relative clauses can also be refuted by arguing the fact that there is not a single properly produced pied-piped finite who relative clause in COHA (with the search string: [nn*] [i*] who, despite the fact that there are numerous cases where who is used as an interrogative pronoun). Considering these facts, it is not persuasive to argue that who is a relative pronoun and that is a complementizer.

Thus, the counter arguments (e.g., Auwera, 1985; Quirk et al., 1985; Sag, 1997: 462-464; Kim \& Sells, 2008: 233-235) remain valid as well.

In addition, English is now an international language. Around the world, non-native speakers, who are learning English, speaking and writing in English, in the EFL or ESL environment, produce countless utterances and sentences daily in their workplaces, schools, or on the Internet. They are learning English from EFL or ESL textbooks. Almost all of these textbooks (e.g., Swan, 1996: 474) explicitly mention that the relative that is a relative pronoun. Considering this reality, the present derivational syntax that studies language phenomena based on synchronic language usage may be doomed to shift its position regarding the status of the relative that.

In short, languages change, and English is no different. The original relative that came from pact, a demonstrative pronoun (see Traugott, 1992: 227; Millward, 2012: 106, 172). It could now be a complementizer as argued by derivational syntax grammarians. However, as time goes by, it will be more reasonable to term the relative that a relative pronoun, considering the persuasive counter arguments going against the view of the relative that as a complementizer, the role of present day English to the people around the world, the influence of EFL and ESL textbooks, and the unbounded usage of English by non-native speakers on the Internet and in the EFL and ESL environment.

\subsection{What to Do with Fundamentally Different Syntactic Analyses}

If we adopt the view of the relative that as a "highly pronominal relativizer" (suggested by Auwera (1985)) or as a relative pronoun, then in case of the derivational generative grammar, there should be some adjustment to the analysis of RRCs including that-RCs . Radford (Radford 2004a: 230) provides a recent analysis of the derivation of 
that-RCs as mentioned in section 2.3, which is repeated below for the readers.

(18) a. [C that $\left.{ }_{\mathrm{WH}, \mathrm{EPP}}\right]$ [TP you [T can] [vp [v trust] who]] (Radford's (116))

b. [CP who [c that ${ }_{\text {WH, EPP }}$ [тP you [T can] [vp [v trust]

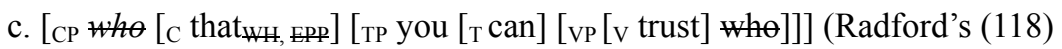

On the other hand, HPSG, which views that as a relative pronoun, hasn't solved the endocentricity issue in labeling the relative clause as HPSG treats it as 'S' with the exocentric concept (see Sag, 1997; Kim \& Sells, 2008: 238).

These syntactic issues are extremely complicated and beyond the scope of this paper.

\subsection{Alternation Issues of that vs. wh-relative Pronouns}

Historically, the relative that went through several spelling changes:

(19) OE paet (an ancestor form of that), ME pet, ME-15 pat (from That, in Oxford English Dictionary online)

According to Millward and Hayes (2012: 262), that was the most dominant relativizer from Middle English until the end of Early Modern English. It used to co-occur with animate and inanimate antecedents, and it could have been used in both RRCs and NRRCs. Relative that is the oldest extant popular form, and wh-relative pronouns are relatively innovative forms. The evolution of the relationship between these unstable alternants, that vs. wh-pronouns, is still in progress with differing degrees of stability due to their distributional variation in regions, among registers, and among interlocutors (depending on their age, social class, education, and gender), and this variation is somehow significant as shown in previous studies (see Sigley, 1997a, 1997b; Biber et al. 1999: 608-630; Moon 2012). Moreover, language-internally speaking, the competition is still going on in case of which and that, compared with the relatively stable who, whose, whom, of which and of whom (see Quirk, 1957; Sigley, 1997b).

However, the present English relativizer system in the formal registers seems to go in a certain direction because of prescriptive grammar books and some guidelines established by journals, newspaper companies and others. that is now used most often with inanimate antecedents in an RRC. who is used mostly after human antecedents. whom is losing its ground except in pied-piped constructions. whose is getting more popular than its alternatives of whom and of which. which is used frequently in NRRCs.

The present English relativizer system of the outer circle and the expanding circle is, on the other hand, expected to show some confusing variance in informal registers due to the influence of EFL and ESL textbooks. Many of these textbooks mention that with respect to that vs. who for human antecedents or which vs. that for inanimate antecedents, both alternants in each case are acceptable, and no explicit guidelines are given for usage. Moreover, non-native speakers' lack of intuition and different learning environment are also important factors in explaining the variance (Note 7). However, as Newbrook (1998) suggests, the relativizer system of the outer and expanding circles in formal written registers may show some fixed distribution in terms of alternation. This is due to their tendency to follow authoritative guidelines in the use of relativizers as non-native speakers lacking intuition to do otherwise.

\subsection{New Directions in Semantic and Discourse Function Analyses}

This subsection summarizes meanings and discourse functions of that-RCs, mentioned in subsections 2.5 and 2.6, and then, reviews the validity of these classifications and possibility of expansion or reduction of the classifications by reviewing the sampled corpus data of the British component of the International Corpus of English (ICE-GB).

\subsubsection{Methodology}

In the subsection 2.5, it is stated that previous studies have found the following meanings of that-RCs: intersective meaning; partitive meaning; non-restrictive meaning; conditional meaning; and essential contextual meaning.

The subsection 2.6 showed that previous studies have found the following discourse functions of that-RCs: characterization; anchoring; description; classification; identification; evaluation; persuasion; scope statement; and elaboration.

It is certain that some of these meanings and discourse functions overlap in terms of content and simply carry different labels, and that each case found in corpus data can be subjectively judged with no objective criteria. However, it is worth reviewing the validity of these classifications with the possibility of expansion or reduction of the classifications in mind. To achieve this goal, the ICE-GB corpus (Release 1), which represents British English and contains one million words of spoken and written English, was used owing to its accurate extraction of that-RC cases unlike other corpora. It provides unmatched grammatical annotations and parsing-based search. First, 'text fragment search' and 'FTF' functions were used, that is, that plus rel feature chosen (Note 8). Four registers, 
following the Biber et al.(1999)'s methodology, were chosen: direct conversation; reportage; creative writing; and academic writing. After that, $20 \%$ sampling was carried out for each register. The result is in Table 1. After obtaining the sampled cases in each register, each case was examined one by one, mostly at the case level.

Table 1. that-RCs in four registers in ICE-GB

\begin{tabular}{ccccc}
\hline & Direct Conversation & Reportage & Creative Writing & Academic Writing \\
\hline Tot & 464 & 55 & 53 & 217 \\
$20 \%$ Tot & 98 & 9 & 8 & 36
\end{tabular}

Description: ICE-GB uses line-based sampling rather than case-based sampling, so the number of sampled cases can be slightly different each time sampling is conducted (see Nelson, Wallis, \& Aarts, 2002: 272-273).

\subsubsection{Result and Discussion}

As stated earlier, it has been confirmed that this kind of study is very subjective and lacks objective criteria. For this reason, after reviewing some sampled data, the general findings will be discussed.

First of all, the combination distribution between the head and the that-RC type (e.g., SS, SO) is distinctively different from other registers in the case of direct conversation. While that-RCs in other registers are mostly subject RRCs, that-RCs in direct conversation are used more as object RRCs as in (20). Moreover, in such cases, the subject within a that $\mathrm{RC}$ is usually a personal pronoun.

(20) (From ICE-GB: S1A-041 \#329:1:A)

And the Queen goes but where are the jewels [that you were wearing].

In terms of semantics, the intersective meaning analysis is not enough to cover all types of that-RRCs as in (21).

\section{(21) (From ICE-GB: W2C-005 \#85:3)}

Although Wm Cook, the Sheffield foundry group [that is doing most to revitalize the sector], still has ample benefits from the rationalization of the George Blair acquisition [...]

Here the antecedent, which is an appositive relationship with Wm Cook, is a specific antecedent, almost treatable as a proper noun, which means that there is no intersective relationship between the head and the that-RC. Instead, the that-RC provides a non-restrictive meaning or a partitive meaning (as suggested by Quirk et al., 1985: 290).

Moreover, (22) shows a more puzzling case since the that-RC doesn't seem to hold any of the meanings previously discussed. We are forced to admit a non-restrictive usage of that-RCs. '[that nobody can honestly predict]' can be paraphrased as '[, which nobody can honestly predict]'.

(22) (From ICE-GB: W2C-003 \#30:1)

First, he cannot stand against the leader unless he is fairly sure of a victory [that nobody can honestly predict].

The that RC carries an insertional meaning like that of an insertion construction, and in terms of discourse function, an evaluation or a characterization function of the antecedent $a$ victory.

Regarding discourse functions, it seems that among various factors, the characteristics of each register, information packaging (given vs. new), channel (spoken vs. written), and formality play such important roles that the distribution of discourse functions appears to be different among the four registers since all these factors are closely related to registers themselves.

In the case of direct conversation, Fox and Thompson (1990) argue that the personal pronoun in a that-RC plays a role of anchoring the head to the given information. However, it seems that in (23) the head plays a topic, and the personal pronoun is used to anchor the content of the that-RC to the specific referent of the personal pronoun with respect to the topic as part of a deictic resolution, that is, to orient/anchor/frame the RC content around a speaker, a hearer, someone or something that the interlocutors share. In case of (23), certain things provides a territory or a topic. Regarding the topic, a good bargain is available at a specific place there in your/hearer's case, revealing some information about the topic towards the hearer. It should be noteworthy that you could refer to either a specific hearer or the general public, but in (23) it is on the borderline depending on the context. 


\section{(23) (From ICE-GB: S1A-048 \#340:1:B)}

I mean there're certain things [that you can get cheaper out there].

In the case of novels, the that-RCs seem to be used to describe or characterize events, things, or characters as in (24).

(24) (From ICE-GB: W2F-002 \#117:1)

Against all the cosmic rules and forces [that are there to prevent interference], Fred has opened the way.

This characterization seems to play multiple roles in a certain context or in a certain stage of the story, such as providing an allusion, setting up an event, or carrying a sarcastic tone about the main event in the preceding matrix clause or context. In (24), it seems the that-RC tells readers that something harmful or adventurous might happen to Fred, as Fred did something that was against the cosmic rules and forces which play the role of preventing interference as mentioned in the that-RC. This kind of view is somehow consistent with Kim (1997), who studied discourse functions of Korean relative clauses found in one Korean novel.

In case of reportage, that-RCs tend to play the role of providing background information about the head as in (25).

(25) (From ICE-GB: W2C-010\#79:2)

Muslim militias finished withdrawing their heavy weapons from West Beirut at the start of the week, followed later by the pro-Syrian militias who entered Beirut's Christian hinterland in the wake of the operation [that ousted Gen. Michel Aoun last month].

As shown in (25), the that-RC can have an identification function. This functional category, however, can be subcategorized and can have a different subcategorical function due to the interplay with various factors such as the characteristics of registers, channel, and formality.

The main text function of academic writing is to deliver new or old information to readers from a fresh perspective. In this register, many that-RCs provide background information or carry an identification function about the head. However, what's noteworthy in this register is that unlike the usage of that-RCs in other registers, many that-RCs in this register have epistemic or deontic modals as in (26). This indicates that the distinct discourse functions of that-RCs of this register are to provide a writer's comment, guess, belief, or hypothesis.

\section{(26) (From ICE-GB: W2A-025 \#27:1)}

Another tropism [that may be of widespread occurrence], and which is also particularly evident in roots, is a directional response to injury, traumatropism.

In (26) the two relative clauses are stacked, one that-RRC and the other $w h$-NRRC. It is a commonly shared view that in a stacked relative clause construction, the first relative clause should be introduced by that-RRC and the next relative clause should be done by $w h$-NRRC. (26) looks like an ordinary stacked relative clause construction. However, while the that-RRC has an epistemic meaning, the wh-NRRC delivers an assertion. This could imply that that-RRCs and $w h$-RRCs may have different discourse functions, even in the RRC usage.

In general, with respect to semantics, there are some cases that cannot be explained with the meanings that previous studies have indicated. One of the main reasons relates to the vestige of that-RCs' old usage as an NRRC. Concerning discourse functions in four registers, that-RCs interact with various factors such as register inherent properties, formality, and channel, resulting in some interestingly distinctive discourse functions and distributions among registers.

\section{Delineation of the Identity of that Relative Clauses}

This section will delineate the identity of that relative clauses based on the literature review and corpus findings in section 2 and 3.

1) Historical aspects of relative that (based on That, in Oxford English Dictionary online (OED); Romaine, 1980: 222; Fischer, 1992: 296; Traugott, 1992: 227; Rissanen, 1999: 293-294; Millward \& Hayes, 2012: 106, 172, 262)

i. $\quad$ Spelling changes: OE paet (ancestor of that), ME pet, ME-15 pat (That, from OED)

ii. The oldest extant popular relative pronoun that came from paet, a demonstrative pronoun

iii. The most dominant relativizer from the Middle English until the end of the Early Modern English

iv. It used to co-occur with animate and inanimate antecedents.

v. It could be used in both RRCs and NRRCs. 
2) The status of that: 'a highly pronominal relativizer' or a relative pronoun

3) Syntactic structure of that-RCs: two sharply divided analyses on the generation of that-RCs:

i. Derivational grammarians' perspective: CP introduced by the complementizer that with a wh-relative pronoun having a null spellout at $\mathrm{PF}$

ii. Non-derivational grammarians' perspective (HPSG): 'S', another type of a wh-rel-cl with the that relative pronoun chosen instead of a $w h$-relative pronoun

4) Alternation between a $w h$-relative pronoun and that

i. Tendency in formal registers

a. that for an inanimate antecedent in an RRC

b. who for an animate antecedent

c. whom losing its ground except in pied-piped constructions

d. whose more popular than of whom and of which

e. which used fairly frequently in NRRCs

ii. Variation caused by language-internal factors and language-external factors

iii. Reasons of the popularity of that relativizers in informal registers:

a. In general, that-RCs are more common in informal registers compared to wh-RRCs

b. Possible reasons:

- Historical reasons: the oldest but popular extant relativizer since Middle English

- Language-internal and language-external reasons

- Lexical property reasons of that

5) Semantic meanings:

i. In case of that RRCs: intersective meaning; partitive meaning; conditional meaning; essential contextual meaning

ii. In case of that with NRRC usage: nonrestrictive meanings that need to be further explored

a. A possible meaning with NRRC usage: insertional meaning

6) Discourse functions

i. With possibilities of the functional overlap: characterization; anchoring; description; classification; identification; evaluation; persuasion; scope statement; and elaboration

ii. The interaction between register-related factors and that-RC discourse functions, resulting in the necessity of subcategories and their distinct distributions among different registers despite the fact that some common functions such as identification are found in all registers. The following show distinct distribution of subcategories among different registers:

a. In direct conversation: a personal pronoun in that-RCs used for a deictic resolution with respect to the head and the that-RC content. That is, concerning the topic (=the head), the speaker anchors/orients/frames the content of the that-RC around a speaker, a hearer, someone or something that the interlocutors share.

b. In novels: description or characterization of events, things or characters

- Further possible subcategorizations: providing an allusion; setting up an event; carrying a sarcastic tone about the main event in the preceding matrix clause or context

c. In reportage: providing background information and identification

d. In academic writing: providing background information and identification

- $\quad$ Further possible subcategorizations: providing a writer's comment, guess, belief, or hypothesis with epistemic or deontic modals 


\section{Conclusion}

Inerasable doubts and obstacles have arisen in carrying out research on that relative clauses due to the disagreement on the status of relative that, the consequently differing syntactic analyses, ongoing alternation issues between that and wh relatives with the influence from language internal and external factors, the remnant of the old usage of that-RCs as NRRCs, consequently expandable semantic meanings and discourse functions, and different subjective categorical classifications in terms of semantics and discourse functions.

Regarding these issues, this study has had three goals: i) to conduct a comprehensive literature review and examine these issues qualitatively, with the aid of corpora (ICE-GB and COHA used); ii) to provide some insight and resolutions, if possible, to each issue, iii) to broaden the horizons of delineating the identity of that relative clauses more comprehensively than before. To achieve the three goals, this study reviewed relevant literature comprehensively and critically and undertook qualitative corpus research with the aid of corpora (ICE-GB and COHA). The main findings and some implications of this study are as follows:

1) The status of that: although no counter evidence against Radford's reasons, mentioned in section 2.2, is found in COHA except the genitive that's, counter arguments against Radford's reasons are still valid. Moreover, considering the present role of English as an international language, the influence of EFL and ESL textbooks, and the immeasurable usage of English by non-native speakers, the relative that is doomed to be considered as either "a highly pronominal relativizer" (as suggested by Auwera (1985) or as a relative pronoun.

2) Fundamentally different syntactic analyses: derivational generative grammar should consider the possibility that that-RCs are relative clauses introduced by a relative pronoun or "a highly pronominal relativizer". If this is true, then it should be willing to adjust its analysis of that-RCs instead of pursuing "a linguists' artifact" as Jacobsson (1994: 194) suggests, that is, instead of pursuing a theory-internally motivated artifact. On the other hand, non-derivational generative grammar should come up with a solution to the endocentricity issue instead of labeling the relative clause as ' $\mathrm{S}$ ' with the exocentric concept.

3) Alternation issues of that vs. wh-relative pronouns: the present English relativizer system of the inner, outer and expanding circles is expected to show some stable distribution in formal registers due to authoritative guidelines by journals, newspaper companies and others. However, the variation in informal registers is expected to differ among the inner, outer, and expanding circles because of both the EFL and ESL textbooks' loose explanations of the alternation issue, non-native speakers' lack of intuition, and different learning environment.

4) Semantic meanings: that-RRCs have intersective meanings, partitive meanings, conditional meanings, and essential contextual meanings. that-NRRCs have nonrestrictive meanings such as insertional meanings.

5) Discourse functions with possibilities of functional overlap: characterization; anchoring; description; classification; identification; evaluation; persuasion; scope statement; and elaboration. Due to the interaction between register-related factors and that-RC discourse functions, there is a necessity to create subcategories, which have distinct distributions among different registers

Despite the fact that this study used a limited scale of data, it provides a more comprehensive examination of that-RCs and illuminates areas to target for further study. First of all, in the present world where English is an international language used in business, ordinary life, and daily communication online and offline, will the relative that status completely change into that of a relative pronoun? It seems that the status of relative that is heading in that direction, but further studies covering the inner, external, expanding circles' that relativizer usage are needed. Second, due to the changing nature of language, alternation, syntax, semantics, and discourse function analyses should keep up with the dynamic identity of that relative clauses, which means there is more work for researchers to do regarding the identity of that relative clauses.

It is my hope that this study has achieved its final goal: expanding the horizons of delineating the identity of that relative clauses more comprehensively, so that it may prove helpful in subsequent research.

\section{Acknowledgements}

I want to express my deepest gratitude to Logan Drury and Natalie Grant for the language help and their insightful comments.

\section{References}

Auwera, J. V. D. (1985). "Relative That": A Centennial Dispute. Journal of Linguistics, 21(1), 149-179. http://dx.doi.org/10.1017/S0022226700010069

Ball, C. N. (1996). A diachronic study of relative markers in spoken and written English. Language Variation and Change, 8, 227-258. http://dx.doi.org/10.1017/S0954394500001150 
Bhatt, R. (2002). The Raising Analysis of Relative Clauses: Evidence from Adjectival Modification. Natural Language Semantics, 10, 43-90. http://dx.doi.org/10.1023/A:1015536226396

Biber, D., Johansson, S., Leech, G., Conrad, S., \& Finegan, E. (1999). Longman Grammar of Spoken and Written English. London: Longman.

Chomsky, N. (1995). The Minimalist Program. Cambridge, Mass.: MIT Press.

Culicover, P. (2009). Natural Language Syntax. NY: Oxford University Press.

Culicover, P. W. (2011). A reconsideration of English relative constructions. Constructions, 2. [Online] Available: http://elanguage.net/journals/index.php/constructions/article/viewArticle/2784

Davies, M. (2010-). The Corpus of Historical American English: 400 million words, 1810-2009. [Online] Available: http://corpus.byu.edu/coha/

De Haan, P. (1987). Relative Clauses in indefinite noun phrases. English Studies, 68(2), 171-190. http://dx.doi.org/10.1080/00138388708598504

Denison, D. (1998). Syntax. In S. Romaine (Ed.), The Cambridge History of the English Language (Vol. 4, pp. 92-329). Cambridge: Cambridge University Press.

De Vries, M. (2002). The syntax of relativization. (Doctoral dissertation, University of Amsterdam). [Online] Available: http://odur.let.rug.nl/ dvries/pdf/proefschrift-mdevries.pdf

Diessel, H., \& Tomasello, M. (2005). A New Look at the Acquisition of Relative Clauses. Language, 81(4), 882-906. http://dx.doi.org/10.1353/lan.2005.0169

Fischer, O. (1992). Syntax. In N. Blake (Ed.), The Cambridge History of the English Language (Vol. 2, pp. 207-408). Cambridge: Cambridge University Press. http://dx.doi.org/10.1017/CHOL9780521264754.005

Fox, B. A., \& Thompson, S. A. (1990). A discourse explanation of the grammar of relative clauses in English conversation. Language, 66, 297-316. http://dx.doi.org/10.2307/414888

Haegeman, L., \& Gue'ron, J. (1999). English grammar: A Generative Perspective. Blackwell. Oxford.

Hardy, D., \& Milton, K. (1994). The distribution and function of relative clauses in literature. Pragmatics and Language Learning. Monograph Series (Vol. 5, pp. 247-265). University of Illinois: Urbana, IL.

Hornstein, N., Nunes, J., \& Grohmann, K. K. (2005). Understanding minimalism. Cambridge: Cambridge University Press. http://dx.doi.org/10.1017/CBO9780511840678

Huddleston, R. D., \& Pullum, G. K. (2002). The Cambridge grammar of the English language. Cambridge, UK; New York: Cambridge University Press.

Jacobsson, B. (1994). Nonrestrictive relative that-clauses revisited 1. Studia Neophilologica, 66(2), 181-195. http://dx.doi.org/10.1080/00393279408588139

Jaeger, T. F., \& Wasow, T. (2006). Processing as a source of accessibility effects on variation. In R. T. Cover \& Y. Kim (Eds.), Proceedings of the 31st annual meeting of the Berkeley Linguistic Society (pp. 169-180). Ann Arbor, MN: Sheridan Books.

Jeon, Y. S., Shin, J. Y., \& Kim, K. H. (2007). Prosodic Disambiguation in English Relative Clause Attachment. The Linguistics Association of Korea Journal, 15(2), 165-186.

Jespersen, O., (1961). A Modern English Grammar on Historical Principles. Part III. George Allen \& Unwin, London; Ejnar Munksgaard, Copenhagen.

Kim, H. S. (1997). Poetics of Relative Clauses in the Novel - Discourse, Textual Functions of Referential Expressions. The Journal of Language and Literature 16, 81-124.

Kim, J. B. \& Sells, P. (2008). English Syntax: An Introduction. CSLI Publications, Stanford CA.

Lee, M. S. (2008). The Role of Structural Complexity in Learning English Relative Clauses. Korean Journal of Linguistics, 33(3), 481-497.

Lee, S. B. (1994). A Semantic Interpretation of Generic NPs in Relative Clauses. Language Research, 30(1), 25-40.

Millward, C. M. \& Hayes, M. (2012). A Biography of the English Language. 3rd ed. Boston: Wadsworth.

Moon, G. G. S. (2012). Observations and Remarks on Relative Pronoun Variation in English. Linguistic Research 29(2), 281-297.

Nelson, G., Wallis, S., \& Aarts, B. (2002). Exploring Natural Language: Working with the British Component of the International Corpus of English. Amsterdam: John Benjamins.

Newbrook, M. (1998). Which way? That way? Variation and ongoing changes in the English relative clause. World Englishes, I 7, (1), 43-59. http://dx.doi.org/10.1111/1467-971X.00081 
Quirk, R. (1957). Relative clauses in educated spoken English 1. English Studies, 38(1-6), 97-109. http://dx.doi.org/10.1080/00138385708596993

Quirk, R., Greenbaum, S., Leech, G., \& Svartvik, J. (1985). A Comprehensive Grammar of the English Language. London: Longman.

Radford, A. (2004a). Minimalist Syntax: Exploring the structure of English. Cambridge: Cambridge University Press. http://dx.doi.org/10.1017/CBO9780511811319

Radford, A. (2004b). English Syntax: An Introduction. Cambridge: Cambridge University Press. http://dx.doi.org/10.1017/CBO9780511841675

Radford, A. (2009). Analysing English Sentences: A Minimalist Approach. Cambridge: Cambridge University Press. http://dx.doi.org/10.1017/CBO9780511801617

Rissanen, M. (1999). Syntax. In R. Lass (Ed.), The Cambridge History of the English Language (Vol. 3, pp. 187-331). Cambridge: Cambridge University Press.

Romaine, S. (1980). The Relative Clause Marker in Scots English: Diffusion, Complexity, and Style as Dimensions of Syntactic Change. Language in Society, 9(2), 221-247. http://dx.doi.org/10.1017/S004740450000806X

Sag, I. A. (1997). English relative clause constructions. Journal of Linguistics, 33(2), 431-484. http://dx.doi.org/10.1017/S002222679700652X

Sigley, R. (1997a). The influence of formality and channel on relative pronoun choice in New Zealand English. English Language and Linguistics, 1, 207-232. http://dx.doi.org/10.1017/S1360674300000514

Sigley, R. (1997b). Choosing your relatives: Relative clauses in New Zealand English. Victoria: Victoria University dissertation.

Soh, D. Y. (1995). The Semantics of English Relative Clauses. Linguistic Research 13, 13-38.

Sonoda, K. (2006). The Nonrestrictive Relative That. Health Science Research. 19(1), 1-5. [Online] Available: http://hdl.handle.net/10069/9770

Swan, M. (1996). Practical English Usage. Oxford: Oxford University Press.

That (n.d.). In Oxford English dictionary. Retrieved September 3, 2012, from http://dictionary.oed.com.

Traugott, E. (1992). Syntax. In R. Hogg (Ed.), The Cambridge History of the English Language (Vol. 1, pp. 168-289). Cambridge: Cambridge University Press. http://dx.doi.org/10.1017/CHOL9780521264747.005

Tse, P., \& Hyland, K. (2010). Claiming a territory: relative clauses in journal descriptions. Journal of Pragmatics. 42: 1880-1889. http://dx.doi.org/10.1016/j.pragma.2009.12.025

Wiesemann, L. M. (2009). The function of Spanish and English relative clauses in discourse and their segmentation in Centering Theory (Doctoral dissertation, Simon Fraser University). [Online] Available: http://summit.sfu.ca/item/9831

\section{Notes}

Note 1 . In case of 4) and 5), the cited studies are generally concerned with all types of restrictive relative clauses including that relative clauses.

Note 2. According to Bhatt (2002), there are three competing analyses on the origin of the head NP of the head adjunct phrase (i.e. the origin of the antecedent of a relative clause): head external analysis; head raising analysis; and matching analysis.

Note 3. See Quirk et al. (1985) and Huddleston and Pullum (2002) for the fundamentals of relative clauses

Note 4. Kim (1997) examined a Korean novel and discussed context-oriented specific discourse functions of Korean relative clauses.

Note 5. Davies (2010-) shows how to cite COHA at http://corpus.byu.edu/faq.asp\#cite.

Note 6. Text source information: date 1882. Title: Sonnets and canzonets. Author: Alcott, Amos Bronson, 1799-1888

Note 7. Natalie Grant, who offered the language help for this paper, mentioned this insightful factor of learning environment that I neglected to pay attention to.

Note 8. ICE stands for International Corpus of English, corpora being expanded to examine the variation of World Englishes. See http://ice-corpora.net/ice/. 